\title{
Is sociologie klaar voor de mediasamenleving?
}

\author{
Giselinde Kuipers
}

SOC $14(2 / 3): 223-242$

DOI: $10.5117 /$ SOC2018.2/3.008.KUIP

\begin{abstract}
Is sociology ready for media society? A quick survey of recent sociology journals shows that as far as sociologists are concerned, social life is not very different from how it was in the 1980s: primarily based on face-to-face interactions, written communication, print media and an incidental phone call. The essay then presents a 'bare bones' version of sociology to show how the recent processes of accelerated mediatisation affects the basic ingredients of sociological analysis - interaction, culture and social structure - as well as the relation between these ingredients. It ends with an invitation to sociologists. For each study you do: ask yourself could this be done with the same methods or concepts in 1975 ? If so, consider adapting your design or conceptual framework to incorporate at least some elements related to the recent wave of mediatisation.
\end{abstract}

Keywords: sociologie, media, mediatisering, sociologische tijdschriften, micro en macro

They took the credit for your second symphony re-written by machine and new technology and now I understand the problems you can see The Bugles - Video Killed the Radio Star (1979)

\section{Media maken een eind aan de mop}

Het onderwerp van mijn proefschrift sterft uit. In 2001 promoveerde ik op een proefschrift over moppen. In 2006 verscheen de bewerkte en uitgebreide Amerikaanse versie. Kort voor het verscheen schreef de New York 
Times: 'Seriously, the joke is dead.' (St. John 2005). Ook folklore- en humoronderzoekers meldden de verdwijning van de mop (Chiaro 2017; Oring 2016). En een replicatie van mijn afstudeeronderzoek uit 1995 liet zien dat Nederlandse middelbare scholieren in 2012 minder moppen kenden dan zeventien jaar eerder (Kuipers en Van der Ent 2016).

Het uitsterven van de mop wordt algemeen geweten aan de opkomst van de media. Al tijdens mijn onderzoek hoorde ik dat door de televisie minder behoefte was aan mensen die een lange avond in gezelschap konden vullen met moppen, verhalen en anekdotes. Met de opkomst van het internet kwamen er nog meer manieren om sociale tijd te vullen: samen gamen, filmpjes kijken op computer of smartphone, tussendoor even appen, of - populair onder hogeropgeleiden - het gesprek steeds aanvullen met snel op internet opgezochte weetjes. ('Even opzoeken wat er van die acteur/politicus/schrijver geworden is... Oh, en weet je met wie die nu is? En wisten jullie wat díe nu doet...!?')

Door mediatisering professionaliseerde ook de productie van humor. De moppentappende oom steekt bleek af bij een geoefende, geregisseerde, professioneel gefilmde en gemonteerde komiek. De combinatie van mediatisering en professionalisering leidde bovendien tot een explosie van nieuwe humoristische genres, van de sitcom en de standup tot het gifje en de meme. Zoals dat gaat bij uitsterven: andere levensvormen zijn beter aangepast aan de nieuwe omgeving. Maar met de mop verdwijnen ook andere dingen: het vermogen om als amateur de aandacht van een gezelschap vast te houden met je vertelkunst, om in je eigen hoofd een repertoire van samenhangende verhalen te bewaren, om als groep elkaar te amuseren met het uitwisselen van zo goed mogelijk vertelde - niet noodzakelijkerwijs nieuwe - verhalen. Zo kalft een eeuwenoude, bloeiende vertelcultuur af.

Het uitsterven van de mop is misschien geen groot nieuws; voor sommigen misschien zelfs goed nieuws. Maar het is een symptoom van iets groters: hoe ingrijpend ons sociale leven verandert als gevolg van de alomvattende invloed van elektronische media, van televisie tot smartphone. Iemand die vanuit 1985 naar het heden zou worden getransporteerd zou weinig begrijpen van wat zij ziet. Iedereen gebogen over kleine verlichte platte doosjes, soms verbonden met een platte typmachine of een draadje naar een oor. Nog verbaasder zou deze jaren-tachtiger zijn als je uit zou leggen dat deze doosjes verbinding maken met een parallelle wereld waarin je niet alleen het equivalent van duizenden Winkler-Prins-encyclopedieën kan raadplegen, televisie kan kijken, radio luisteren en de krant lezen, maar 
ook een partner kan vinden, boodschappen doen, je eigen teksten publiceren, videotelefoneren met het andere eind van de wereld en permanent in contact kan staan met tientallen mensen.

De sociologie als discipline lijkt op deze jaren-tachtiger: terechtgekomen in een gemediatiseerde samenleving, met ontoereikende concepten en methoden om deze te begrijpen. Hedendaagse sociologische tijdschriften schrijven zelden over elektronische media. Als het al over media gaat, hebben sociologen het eerder over de krant en televisie dan over smartphones en internet.

Dit essay gaat over de vraag of sociologie klaar is voor de mediasamenleving. Zo'n vraag stel je niet om haar met een volmondig 'ja' te beantwoorden. Als discipline besteedt sociologie wat mij betreft te weinig aandacht aan media. Niet aan de oude, zoals krant en televisie, en al helemaal niet aan ook-al-niet-meer-zo nieuwe media als internet en smartphone. Voor zover sociologen over media schrijven, is vooral binnen gespecialiseerde velden: mediasociologen onderzoeken mediaproductie of -consumptie (Revers en Brienza 2014), digitale sociologen kijken naar het leven online (Daniels en Gregory 2016; Golder en Macy 2014).

Maar media zijn allang niet meer een afzonderlijk 'veld' zoals literatuur, kunst, sport of onderwijs. Alle aspecten van het dagelijks leven zijn doordrongen van media, van alledaagse interactie tot werk, consumptie, amusement of bestuur. Daarmee zijn ook de 'basisingrediënten' van de sociologie - sociale interactie, cultuur en sociale structuur - veranderd.

\section{Een blinde vlek voor media}

Tabel 1 toont een overzicht van artikelen uit de laatste jaargang (september 2017 tot en met september 2018 ${ }^{1}$ ) van American Sociological Review, British Journal of Sociology, European Societies en Sociologie waarin 'media' in het algemeen, of een specifiek medium genoemd zijn in abstract of keywords. Dit zijn vier algemene tijdschriften uit respectievelijk de VS, het VK, Europa en Nederland. Hoewel divers in publiek, kwaliteit en impact, zijn ze niet eenkennig qua methoden, thema's of sociologische subvelden. Uit de tabel blijkt dat media in deze tijdschrift weinig aan bod komen: net 9\% van 155 artikelen.

Tabel 2 laat zien dat media in sociologische artikelen op vier manieren aan bod komen. In vier gevallen fungeren 'de media' of 'digitisering' als context: 
Tabel 1 Expliciete verwijzing naar media in sociologische tijdschriften

\begin{tabular}{|c|c|c|c|c|c|}
\hline & $A S R$ & BJS & $E S$ & Sociologie & Totaal \\
\hline Media in abstract of keywords & 5 & 5 & 2 & 2 & 14 \\
\hline Welke media? & & & & & \\
\hline Printmedia (tijdschrift, krant) & 1 & & 2 & & 3 \\
\hline Telefoon & 1 & & & & 1 \\
\hline Televisie & & & & 1 & \\
\hline Who's who? & 1 & & & & 1 \\
\hline 'de media' & & 2 & & 1 & 2 \\
\hline 'digitisering' & & 1 & & & \\
\hline ICT/infrastructuur & & 1 & & & 1 \\
\hline Sociale media (Facebook etc.) & 1 & & & & 1 \\
\hline Big data & 1 & & & & 1 \\
\hline Computerondersteunde methode & 1 & 1 & & & 2 \\
\hline Totaal artikelen in jaargang & 41 & 56 & 33 & 25 & 155 \\
\hline$\%$ over media & $12 \%$ & $9 \%$ & $6 \%$ & $8 \%$ & $9 \%$ \\
\hline
\end{tabular}

Tabel 2 Hoe worden media gebruikt in sociologische artikelen

\begin{tabular}{|c|c|c|c|c|}
\hline Hoe? & Oude media & Nieuwe media & Alle & Totaal \\
\hline Context & & 1 & 3 & 4 \\
\hline Methode & 2 & 2 & & 4 \\
\hline Spiegel van de samenleving & 4 & & & 4 \\
\hline Onderwerp van analyse & & 3 & & 3 \\
\hline
\end{tabular}

Media and politics speak in alarmist discourse about [...] conspiracy theories (Harambam 2017).

[...] that these kinds of conditions have defined musicians' working practices over much longer periods of time (though they may have intensified due to well-documented changes to the music industry brought about by digitization and disintermediation) (Haynes en Marshall 2018).

Vaak veronderstellen artikelen een gemediatiseerde context zonder deze te noemen. Abstracts verwijzen regelmatig naar 'public' (sphere, sociology, life, opinion, discourse...) en 'publics'. Beide bestaan bij gratie van media. Ook het veelgebruikte 'discourse' is zonder media lastig voorstelbaar.

Media figureren ook als onderdeel van methode: 'callback' met telefoon in een veldexperiment, het gebruik van 'tools from computer science' en 'computer-supported' analyse van gegevens. Ook hier geldt dat er in artikelen meer aan media zit dan de abstracts laten zien. Dataverzameling en -analyse is bijna niet denkbaar zonder software, datasets en Google Scholar. 
Dit spreekt zo vanzelf, dat waar het abstract dit noemt het een wat wereldvreemde indruk maakt.

Oude media fungeren vaakals 'spiegel'van de samenleving. Onderzoekers kijken naar media om maatschappelijke verschijnselen op het spoor te komen: de representatie van wetenschap in kranten, de populariteit van muzikale genres in de ranglijsten van het muziektijdschrift Billboard. Noordzij, van Eijck en Berkers (2016) lieten reality-televisieprogramma's zien om mensen uitspraken over klasse te ontlokken.

Slechts drie abstracts noemen nieuwe media. Waar dit gebeurt, is dit meteen het onderwerp van het artikel. Een artikel over ICT-infrastructuur (Boucas 2017), een over Facebook (Bail et al. 2017), en een over 'big data analytics' bij de politie (Brayne 2017).

De sociologie heeft, kortom, een blinde vlek voor media. Media figureren weinig, en dan eerder als context, methode of spiegel dan als onderwerp. Het gaat bovendien maar heel zelden over media die niet bestonden voor 1980. In sociologische tijdschriften zou het, qua media, inderdaad bijna 1985 kunnen zijn.

Maar is dit een probleem? Je zou kunnen zeggen: dit onderzoek valt onder mediastudies en communicatiewetenschap, specialisatie is nu eenmaal nodig. Bovendien zijn er heus algemene sociologen die over media schrijven - denk aan Manuel Castells. En we hebben de kleine maar bloeiende vakgebieden van de media- en digitale sociologie, die een brug slaan tussen sociologie en mediastudies.

Mediatisering is echter te belangrijk om aan de communicatie- en mediawetenschappers over te laten. Deze disciplines stellen andere vragen dan sociologie, onder meer omdat ze voortkomen uit andere velden: de wortels van communicatiewetenschap liggen in politicologie en psychologie, mediastudies wortelt in de geesteswetenschappen. De beperkte aandacht van sociologen voor media maakt bovendien dat sociologen over het hoofd zien dat hun onderzoeksobject ingrijpend verandert. Deze verandering vergt een herijking van de methodologische en conceptuele 'gereedschappen' van onze discipline.

\section{Media en het sociologisch denkraam}

Het afgelopen jaar heb ik ter voorbereiding van ons tweetalige bachelorprogramma een groot aantal sociologie-inleidingen doorgenomen. Dit was verhelderend: ik zag sociologie teruggebracht tot de simpelste basisbeginselen. 
Figuur 1 laat zien hoe deze uitgeklede versie van sociologie er volgens mij uitziet. Let wel: dit is mijn schematische samenvatting van het sociologisch denkraam in overwegend Angelsaksische handboeken. Het is denkelijk geen toeval dat dit schema wel iets wegheeft van de schema's van Talcott Parsons (hoewel die de voorkeur gaf aan vierkanten boven driehoeken). Juist door zijn simpelheid helpt deze figuur om na te denken over de plaats van media in het 'mainstream' sociologische denkraam.

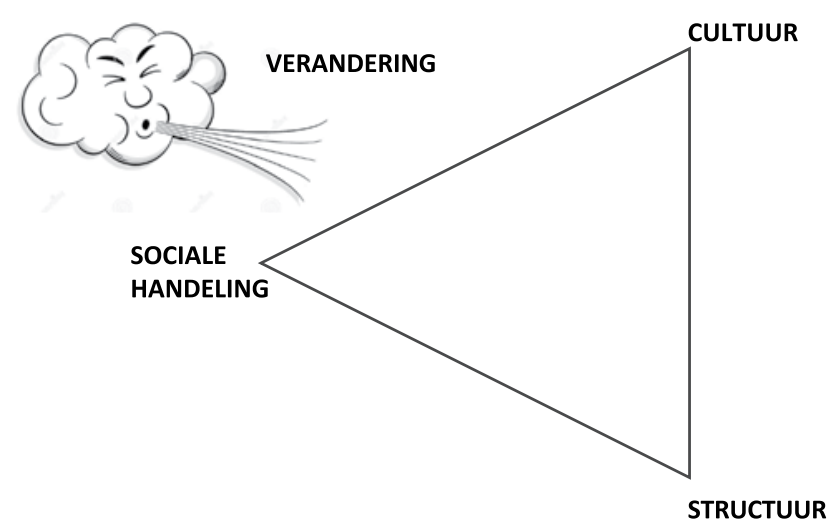

Figuur 1 Het sociologisch denkraam

Sociologische verklaringen zijn in de handboeken een wisselwerking tussen drie brede conceptuele categorieën: sociale handeling, cultuur en structuur. 'Cultuur' gaat over alle gedeelde en aangeleerde kennis en vaardigheden, en wordt aangeduid met termen als normen, waarden, betekenis, bovenbouw, repertoire, discours, ethos of geloofssysteem. 'Structuur' gaat over duurzame sociale verhoudingen, en heet bijvoorbeeld basis, institutie, netwerk, interdependentie of sociale relaties, en soms ook politiek, economie, politieke economie of machtsverhoudingen. Omdat we de wereld sociologisch bekijken, is elke menselijke handeling een sociale handeling, gevormd door samenleven en (tenminste deels) gericht op anderen. De handboeken noemen dit bijvoorbeeld interactie, gedrag, sociaal gedrag, conversatie, ritueel of performance, maar ook wel keuze, beslissing, respons, mening of attitude.

Deze drie elementen zijn met elkaar verbonden en kunnen elkaar wederzijds beïnvloeden. Theoretische benaderingen worden vaak uitgelegd in deze termen. Webers protestantse ethiek gaat van cultuur (protestantisme) naar sociale handeling (ascetisme) naar structuur (kapitalisme). Bourdieu gaat van structuur (machtsverhoudingen in velden) via cultuur (posities 
van culturele objecten en smaken in velden) naar sociale handeling (habitus). De rationele-keuzebenaderingen gaat van sociale handeling (keuze) naar structuur (instituties), vaak via cultuur (normen). De handboeken presenteren veranderingsprocessen zoals modernisering, globalisering, individualisering, urbanisering vaak als min of meer losstaand van cultuur, structuur en sociale handeling. Daarom zet ik verandering buiten het kader: het wolkje linksboven.

Alle sociologisch te verklaren of begrijpen verschijnselen (de explananda), van echtscheidingspercentages tot een voorkeur voor moppen, staan als het ware in het midden van de figuur. De wisselwerking tussen de drie hoeken en het wolkje linksboven vormen dan samen het explanans: de grotere sociale constellatie die ons helpt het specifieke geval te begrijpen.

Nogmaals: een versimpeld schema, maar het helpt wel de sociologische blinde vlek voor media te begrijpen. In dit figuur kan media verschijnen als een sociale verandering en dus als 'context' (wolkje). Als een culturele vorm of invloed (rechtsboven), een sociaal veld of machtsbron (rechtsonder), of als data, casus of 'spiegel' (middenin). Media kunnen ook geanalyseerd worden als onderdeel van een sociale handeling of interactie (linksonder). Maar juist dat stuk sociale werkelijkheid is overgedaan aan media- en communicatiewetenschappers.

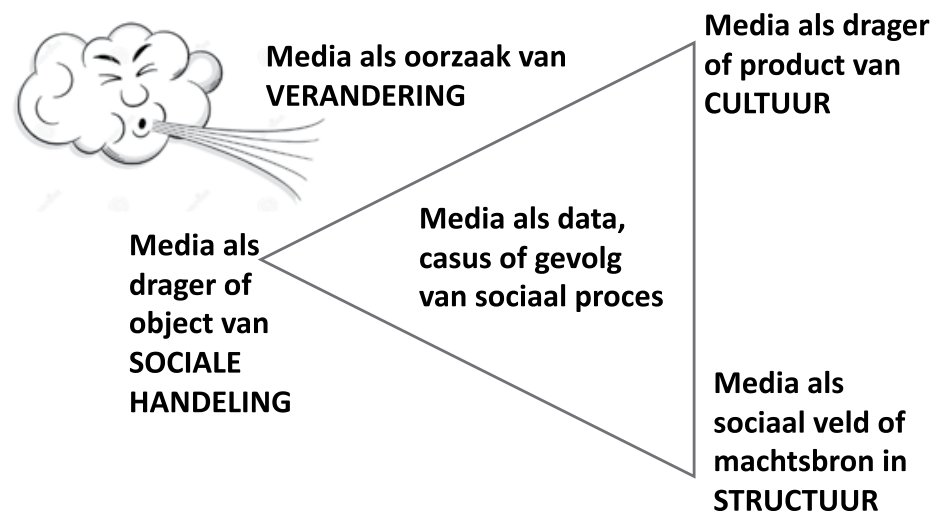

Figuur 2 Media in het sociologisch denkraam

Media kunnen, in stukjes gehakt, op allerlei plaatsen in het model worden ondergebracht. Dit is dan ook precies wat er in sociologische tijdschriften gebeurt. Maar deze fragmentatie van media, als data, oorzaak, gevolg, cultuur, structuur of interactie, vertroebelt ons zicht op de alomtegenwoordigheid van media in de hedendaagse samenleving. 
Een betere oplossing is dan om niet te spreken van 'media', als ding (of dingen), maar te spreken van een proces, mediatisering (Couldry en Hepp 2017), dat al deze losse elementen, en de relaties daartussen, beïnvloedt. Dit proces is echter geen wolkje linksboven. In mijn sociologie-opvatting is verandering niet iets externs (behalve als het gaat om een meteorietinslag). Mediatisering is een proces dat voortkomt uit de sociale wereld zelf. Het zou er dan ongeveer uitzien als figuur 3 , hieronder.

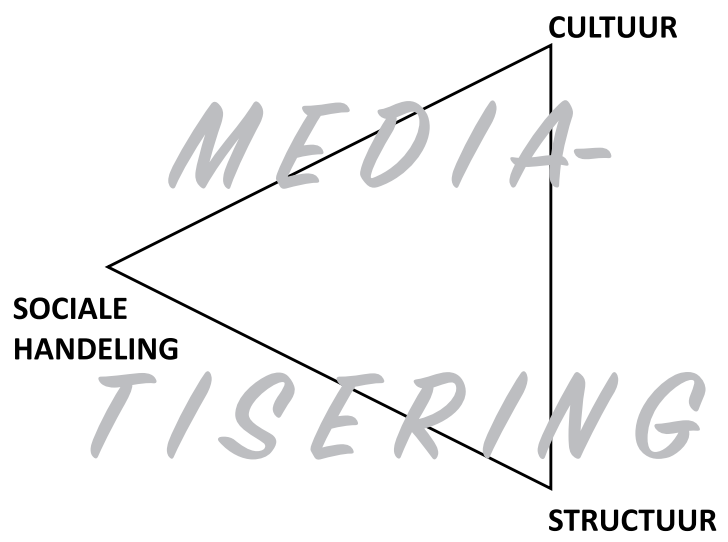

Figuur3 Mediatiseringen het sociologischdenkraam

Aan de hand van figuur 3 zal ik doordenken hoe niet alleen de afzonderlijke elementen in dit schema, maar ook relaties daartussen verschuiven onder invloed van een alomvattend proces van mediatisering. Dit proces voltrekt zich niet buiten, maar in de wisselwerking tussen deze elementen.

\section{Mediatisering en sociale (inter)actie}

Het wordt weleens over het hoofd gezien, maar elk sociologisch onderzoek is gebaseerd op concrete acties, en vooral interacties van mensen. Hierin spelen allerlei media een steeds grotere rol. Dit is goed te zien aan de sociale interacties waar sociologen zich op baseren - de gesprekken, surveys en experimenten waarin onze data worden gegenereerd. Surveys en experimenten gaan tegenwoordig bijna allemaal via computers of smartphones. Interview- en etnografische studies combineren face-to-face-interactie steeds vaker met gemedieerde interacties. Reflectie op de mediatisering van onze data is er weinig. Zo is het vaak moeilijk te achterhalen hoe de data voor grote datasets zijn verzameld: in een gesprek, via de telefoon, via een papieren vragenlijst, of via een computer? 
Media- en communicatiewetenschappers hebben laten zien dat er grote verschillen kunnen zijn tussen wel of niet elektronisch gemedieerde communicatie, en ook tussen communicatie via verschillende mediatypes (Boyd 2014; Deuze 2011; Van Dijck 2013a; Robinson 2007) De opkomst van elke medium betekent een leerproces, zowel individueel als collectief (Van Dijck 2013b). We ontwikkelen conventies voor de omgang met diverse media, en leren met vallen en opstaan omgaan met de risico's en mogelijkheden van nieuwe media en nieuwe platformen. Zo had ik vijftien jaar geleden allemaal sanctieregels om te zorgen dat mijn colleges niet verstoord werden door rinkelende en piepende mobiele telefoons. Dat probleem is opgelost. Inmiddels is de uitdaging vooral om te zorgen dat je aandacht niet wordt afgeleid door je eigen telefoon. Dat deze inmiddels doodstille telefoons zijn uitgegroeid zijn tot verlengstuk van mondiale mediaconcerns die ons massaal bespioneren is een kwestie waar we vooralsnog noch individueel, noch als samenleving een oplossing voor hebben.

Een van de opvallende consequenties van de laatste golf van mediatisering - beginnend bij e-mail en internet, voorlopig culminerend in smartphones en sociale media - is dat steeds minder duidelijk is wat de context is van een interactie. We zijn als het ware steeds in meerdere situaties tegelijk. Een van de consequenties hiervan is wat Marwick en Boyd (2011) aanduiden als 'context collapse'. Op sociale media als Facebook of Instagram richten onze performances zich vaak op meerdere contexten en dus publieken tegelijkertijd: je moeder, je baas, vrienden van twintig jaar geleden, journalisten en volledig onbekenden. Het idee van een in tijd, plaats en gezelschap bepaalde 'situatie' waarin een interactie is ingebed komt hiermee op losse schroeven te staan. De 'definitie van de situatie' is wel beschreven als de enige wet van de sociologie: als we een situatie definiëren als echt, is zij echt in haar gevolgen. Als situaties moelijker te definiëren zijn als echt, wat betekent dat dan voor alledaagse interactie?

In deze steeds vager omlijnde, steeds meerlagiger situaties, interacteren we bovendien steeds vaker via, en in toenemende mate ook met apparaten. Interacties worden dus sterk afhankelijk van media, en deze fungeren steeds vaker niet alleen als medium of doorgeefluik, maar ook als boodschapper of gesprekspartner. Zo krijgen de chauffeurs van Uber en de bezorgers van Deliveroo hun werkopdrachten van een app. Zelfs sollicitaties worden gescreend door apps. Ook dit betekent een verschuiving in wat we verstaan onder interactie. Dit verklaart ook de toenemende populariteit van actor-netwerk-theorie. Latour begon immers in de jaren zeventig als met het problematiseren van context, en van de scheiding tussen 
menselijke en niet-menselijke actoren. Dat klinkt nu allang niet meer zo vergezocht als toen.

Eerdere golven van mediatisering - drukpers, radio, televisie - voegden vooral dimensies toe aan de alledaagse interactie (Couldry en Hepp 2017). Alledaagse communicatie bestond nog altijd uit ouderwetse gesprekken. Er kwam alleen steeds meer bij. De laatste golf - digitalisering - raakt aan de interacties zelf. Dit roept de vraag of hoe deze verandering doorwerkt in de samenleving als geheel.

Alles wat wij aanduiden als sociale structuur en als cultuur is niet meer dan steeds herhaalde interacties, vaak met minimale variaties (Collins 2004). Juist deze herhaling maakt dat sociologen op basis van beperkte steekproeven, vaak van geïsoleerde interacties, conclusies durven trekken over hele samenlevingen. Als dit 'basismateriaal' van de samenleving zo sterk verandert, gaan dan niet ook de grotere structuren schuiven? Met deze vraag bevinden we ons middenin het terrein van de sociologie: de grote patronen en regelmatigheden in de samenleving - ofwel het macroniveau - en hoe deze geproduceerd en gereproduceerd worden op het microniveau.

\section{Gemediatiseerde interacties en sociale structuur: van micro naar macro}

We beginnen bij het pad van links naar rechtsonder: hoe kunnen verschuivende interactiepatronen als gevolg van opkomende digitale media leiden tot veranderingen in de sociale structuur? Al sinds de opkomst van het internet is dit het domein van grote verwachtingen, sweeping statements, en journalistieke half-waarheden over global villages en filterbubbels. Sommige grote verwachtingen zijn al ontkracht. Zo is er weinig terecht gekomen van de bottom-up habermasiaanse participatiecultuur die in de jaren negentig voorspeld werd. Tegenwoordig overheersen dystopische scenario's: sociale polarisering en desintegratie, surveillance, verlies van privacy. Recent onderzoek suggereert dat het ook wel weer meevalt met die zogenaamde 'filterbubbel', waardoor we online louter gelijkgestemden zouden tegenkomen (zie bijv. Zuiderveen Borgesius et al. 2016). Maar in alle gevallen gaat het om een vergelijkbare 'route' door figuur 3: als sociale interacties steeds meer gemedieerd zijn, dan zou dat moeten leiden tot verschuivingen in grotere sociale structuren.

Zoals deze voorbeelden laten zien, gaat veel discussie over de sociale consequenties van mediatisering over politiek. Dit komt deels door de 
politicologische roots van veel media- en communicatieonderzoekers. Maar politiek is ook de institutie die met meest zichtbaar geraakt is door de mediatisering. De tumultueuze politieke ontwikkelingen van de afgelopen jaren zijn moeilijk los te zien van de opkomst van genetwerkte, emotierijke, laagdrempelige, manipuleerbare, transnationale, commercieel gedreven sociale en niet-sociale media. Hoe dit nu allemaal precies met elkaar samenhangt zal onderzoekers wellicht nog eeuwen bezighouden. Maar ook andere instituties veranderen ingrijpend - van onderwijs en onderzoek tot de distributie van ons voedsel. En waar alle instituties verschuiven, veranderen ook de grotere sociale verbanden.

Maar in de sociologie blijft het stil. In de discussie over de gevolgen van mediatisering ontbreekt de sociologische 'blik': het zoeken naar grote verbanden, over domeinen en instituties heen, geschraagd door degelijke empirische observatie (zie ook Daniels en Gregory 2016; Revers en Brienza 2018). Wat voor soort van onderliggende mechanismen zien we in de mediatiserende samenleving? Zien we dezelfde ontwikkelingen in verschillende sectoren? In hoeverre is dit een continuering van of een radicale breuk met eerdere patronen? Om maar een voorbeeld te noemen: een opvallend weinig bediscussieerde kwestie met grote sociologische relevantie is de invloed van digitalisering op partnerkeuze (maar zie Potârcă en Mills 2015). Dit gaat steeds vaker via datingsites of apps - nogal een verschuiving ten opzichte van het Algemeen Menselijk Patroon, waarbij partners werden gevonden via sociale netwerken. Aangezien dating letterlijk leidt tot de reproductie van de samenleving, zijn de consequenties verstrekkend. Ik vind het dan ook een blamage dat dit niet alleen weinig is onderzocht, maar dat de meest omvattende studies op dit gebied zijn gedaan door, respectievelijk, economen publicerend in een natuurwetenschappelijk tijdschrift (Ortega en Hergovich 2017) en door een datingsite (geciteerd in Golder en Macy 2014)

Wat sociologen kunnen bieden is een solide theoretische basis om na te denken over micro-macroverbindingen. De theoretische route van handeling naar sociale structuur hoort van oudsher bij twee sociologische paradigma's: de durkheimiaanse/goffmaniaanse microsociologie en de rationele-keuzetheorie. Microsociologie staat centraal in veel onderzoek naar online-interactie (Boyd 2014; Robinson 2007). Maar dit onderzoek blijft vaak op microniveau, en sluit niet aan bij recenter sociologisch werk dat Goffman 'opschaalt' naar grotere verbanden. De meest invloedrijke 'opschaling' is Randall Collins' Interaction Ritual Theory (2004). Collins doet in zijn boek twee tegengestelde voorspellingen over de consequenties van toenemende mediatisering: 
IR theory [interaction ritual theory] has a prediction here too: the more that human social activities are carried out by distance media, at low levels or IR intensity, the less solidarity people will feel; the less respect they will have for shared symbolic objects; and the less enthusiastic personal motivation they will have in the form of EE [emotional energy].

There is a special proviso. It is possible that electronic media of the future might be designed just so that they can target those aspects of human physiology that make IRs work. IRs build up high levels of focused attention and emotional entrainment; conceivably, communications devices of the future could attempt to send [...] just those signals that most enhance these shared experiences. There might well be something dangerous in such devices.

(Collins 2004: 64)

Vooralsnog zijn er weinig studies die deze voorspellingen hebben getoetst. Een duidelijk voorbeeld van de sociologische blinde vlek voor media (zie ook Maloney 2013). Hoewel Collins voorspellingen wat dramatisch aandoen (niet voor niets heeft hij zich na zijn emeritaat ontpopt tot science-fictionschrijver), lijken beide voorspellingen deels uit te komen. Mediatisering leidt zowel tot 'verdunning' van solidariteit, als tot zeer intense bindingen. Dit laatste gaat weliswaar zonder electroden, maar wel met ondersteuning van gedragswetenschappers die adviseren over de beste manier om emotionele betrokkenheid te vergroten. De vraag onder welke condities mediatisering leidt tot grotere of juist kleinere emotionele betrokkenheid, in kleinere of juist groter verbanden, lijkt me sociologisch boeiend, en ook buitengewoon relevant. Vooral lijkt het me een vraag die niet aan marketingonderzoekers, laat staan aan marketingafdelingen van grote techbedrijven, overgelaten mag worden.

De andere klassieke micro-naar-macro-benadering is de rationelekeuzetheorie. Een snelle literatuurzoektocht - dit gebied is wat verder van mijn expertise - laat zien dat sociologen weinig zichtbaar zijn in onderzoek naar rationele keuze, media en online-interactie, en dat rationele-keuzesociologen mediatisering niet identificeren als nieuw of centraal thema (zie bijv. het overzicht van Kroneberg en Kalter 2012). Een klassiek theoretisch thema in de rationele-keuzetheorie als vertrouwen kan bijvoorbeeld op allerlei manieren verbonden worden met vragen over mediatisering (zie bijv. Beldad et al. 2010). Hoe ontstaat vertrouwen in gemedieerde interacties? Hoe wordt dit gevormd door, en hoe beïnvloedt het, vertrouwen in groter verband? In de afgelopen jaren is er - mede door het omstreden onderzoek van Putnam - veel aandacht voor sociaal vertrouwen. Maar ook deze discussie doet nogal 1985 aan: vertrouwen lijkt vooral een kwestie van 
'ouderwetse' instituties en interacties, en waar media aan de orde komen dan vooral als bedreiging van vertrouwen. Terwijl de rationele-keuzetheorie, net als Collins, leidt tot zowel hypothesen over toe- als afname van vertrouwen door mediatisering. Ook hier, kortom, zou de sociologie een fundamentele bijdrage kunnen leveren: door systematisch te onderzoeken hoe vertrouwen werkt in gemediatiseerde tijden, in verschillende domeinen en in de samenleving als geheel, en hoe verschuivingen in interactiepatronen doorwerken in duurzame sociale structuren.

\section{Gemediatiseerde interacties en cultuur: van interactie naar betekenissysteem (en verder)}

We komen nu bij het tweede 'pad' langs de driehoek: van links naar rechtsboven, dus van interactie naar cultuur. Toevoeging van mediatisering aan de route van interactie naar structuur leidde tot een soort sociologische todo-list met nieuwe vragen en nieuwe thema's. Dat is bij deze route anders. 'Mediatisering' kan namelijk niet op dezelfde manier worden 'toegevoegd' aan de verhouding cultuur-interactie. Het is namelijk geen extra ingredient in deze verhouding, zoals het dat (deels) wel is bij interactie en sociale structuur. Het is een verschuiving in een verhouding die altijd al gemedieerd was.

We bevinden ons hier op het terrein van de cultuursociologie: het veld dat zich bezighoudt met de verhouding tussen betekenissystemen en alledaagse interacties. Lange tijd ging deze route vooral van betekenis naar interactie: het protestantisme van Weber, de habitus van Bourdieu, de repertoires van Swidler en Lamont - hoewel ze variëren in mate van agency loopt de verklaringsroute van cultuur naar handeling. De afgelopen tijd verschuift de aandacht naar de rol van interacties in de creatie (en niet alleen reproductie) van cultuur. Dit vertaalt zich in meer actor-netwerktheorie (bijvoorbeeld Rubio 2014), meer netwerkanalyse (Crossley en Bottero 2015) - maar helaas nauwelijks in meer onderzoek naar media. Ik heb het niet expliciet geteld, maar ik denk niet dat cultuursociologische tijdschriften meer aandacht hebben voor media dan algemene sociologische tijdschriften.

Juist in de cultuursociologie is de afwezigheid van media verrassend. Tegenwoordig is de productie van cultuur nauwelijks meer los te denken van mediaproductie. Ook cultuurconsumptie is doordrongen van allerlei media. Hierdoor is de sociologie van kunst en cultuur, of cultuursociologie 'in enge zin', steeds meer een sociologie van de media. Cultuursociologen 
merken dat nauwelijks op. Integendeel, net als 'gewone' sociologen gebruiken cultuursociologen media vooral als context, data en spiegel.

Dat is des te merkwaardiger omdat 'mediëring' - datgene wat media doen - zich in het hart van de cultuursociologie bevindt. Alle dingen waar cultuursociologen zich mee bezighouden, zoals smaken, standaarden, genres, symbolische grenzen, evaluaties, classificaties en rituelen, maar ook normen, waarden, idealen en ongeschreven gedragsregels zijn ingebed in gemedieerde betekenissystemen. Wat we cultuur noemen is ondenkbaar zonder 'media' in de oorspronkelijke betekenis: bemiddelende 'dragers' tussen zender en ontvanger. Ook taal, geld, en twee- en driedimensionale afbeeldingen zijn media in deze zin. Niet alleen maken ze (symbolische) communicatie mogelijk, ze verbreden ook het referentiekader voorbij alledaagse interacties. Media verbinden mensen met andere mensen, en met belevingswerelden voorbij hun eigen ervaring. Zoals Marshall McLuhan betoogde: mediëring is cultuur; dat is wat ons mens maakt (McLuhan 1994).

De introductie van Marshall 'the medium is the message' McLuhan helpt ons om de verhouding tussen media, interactie en cultuur scherper te zien. Zo zien we allereerst dat het recente mediatiseringsproces niet nieuw is, maar een versnelling en intensivering van een langetermijnproces van mediëring. McLuhans perspectief maakt bovendien duidelijk waarom cultuur en interactie niet zo makkelijk te scheiden zijn in 'macro' en 'micro'. Alle interacties worden in feite gemedieerd door cultuur. Het ene is dus geen 'grotere' versie van het andere: cultuur en interactie zijn met elkaar verstrengeld. Een gereïficeerd idee van cultuur, bijvoorbeeld als cultuurgoederen - van boeken en beelden tot memes en gestreamde TV-series - is dan ook misleidend. Boeken, beelden, memes of series zijn eigenlijk ook cultuurmedia: middelen waarmee mensen elkaar boodschappen sturen.

Ik kan dit uitleggen aan de hand van mijn eigen onderzoek naar schoonheid. Gedurende millennia zagen mensen in hun leven misschien maar tientallen, hoogstens honderden afbeeldingen van andere mensen. Tot enkele eeuwen geleden gold dit ook in grote delen van Nederland - waarbij de score voor katholieken beduidend hoger lag dan voor protestanten. Wij zijn geneigd zulke afbeelden te zien als een materiele neerslag van cultuur. Maar het zijn ook media, bemiddelaars in interacties, waarmee mensen elkaar iets willen laten zien. Vroeger, net als vandaag, zijn zulke afbeeldingen vaak esthetisch: bedoeld om mooi te zijn. Ze communiceren en ze normeren. Ze zeggen: dit vind ik mooi. En ze instrueren: kijk, dit is nou mooi.

Tegenwoordig zien mensen op een dag meer afbeeldingen van mensen dan zestiende-eeuwse Nederlanders in hun hele leven. Veel van deze beelden communiceren nog altijd 'dit is mooi'. Maar het zijn er meer dan 
ooit, ze komen tot ons via meer routes dan ooit. Hoewel ze nog altijd worden 'gezonden' en 'ontvangen', is wat we zien steeds vluchtiger en meer geïndividualiseerd: ik deel slechts een klein deel van mijn media-ervaring met anderen. Daardoor is de kans veel groter dat ik er iets anders in zie dan de maker bedoelde. Maar hoewel de schaal en intensiteit anders zijn, is de werking niet principieel anders. Zowel nieuwe, oude, als zeer oude media bemiddelen altijd in interacties, over kortere of langere afstanden (Anderson 2006). Culturele standaarden, ideeën, waarden, normen en raamwerken komen altijd tot ons in gemedieerde interacties tussen mensen en hun dingen.

Vanuit deze optiek zijn mediasociologie en cultuursociologie sterk aan elkaar verwant. Het zou wat al te imperialistisch zijn om hier voor een fusie te pleiten, en dat hoeft ook niet. Ik kan me echter wel goed voorstellen dat als media en mediatisering een centrale plaats krijgen in de sociologie, deze sociologie van media of mediatisering er op termijn ongeveer uit zou zien als de huidige cultuursociologie: met een productieve spanning tussen mediasociologie in 'nauwe' en 'enge' zin. In de cultuursociologie heeft deze splitsing zich voorgedaan sinds de jaren tachtig. Er zijn nu cultuursociologen die kijken naar kunst en cultuur: de velden waarin symbolische productie centraal staat. En er zijn cultuursociologen die cultuur niet bestuderen als apart veld, maar als betekenissysteem, praktijk, cognitie of repertoire. Deze conceptualiseringen weerspiegelen eenzelfde inzicht: cultuur is niet alleen een institutioneel veld, maar een sfeer of aspect van het menselijke handelen dat doorwerkt in alle sociale actie en interactie. De twee subvelden hangen echter nauw samen. In gespecialiseerde velden zijn culturele processen extra zichtbaar, en deze velden hebben een geprivilegieerde positie in de sociale (re)productie van algemene cultuur. 'Enge' en 'brede' cultuursociologen delen daarom theorieën, concepten, methoden, en ook wetenschappelijke en sociale netwerken. Vooral de 'brede' cultuursociologen mengen zich echter ook in algemene sociologische debatten.

Een dergelijke 'dubbele' mediasociologie zou het beste recht doen aan de positie van media in hedendaagse samenlevingen. Allereerst is het veld van 'de media' een centrale institutie en een centraal veld in hedendaagse samenlevingen. Dit is goeddeels het domein van de huidige mediasociologie. Daarnaast is er een breder proces van 'mediatisering' - het groeiende belang van elektronische en digitale media voor alle maatschappelijke sectoren. Sociologisch onderzoek hiernaar verbindt alle drie de zijden van de driehoek: interactie, cultuur en sociale structuur. Onderzoek en theorievorming langs de derde zijde - van cultuur naar sociale structuur en andersom - is meer het domein van algemene sociologie en bredere paradigma's. 
En dan is er nog het grotere sociale feit van de mediëring. Het doordenken van de rol van media in het sociologisch denkraam heeft mij niet alleen bewust gemaakt van een blinde vlek van de sociologie. Nog groter is de blinde vlek in de cultuursociologie, en het betreft het begrip van ons eigen centrale concept: cultuur.

\section{Conclusie: de sociologie is niet klaar voor de mediasamenleving. Wat nu?}

De sociologie is niet klaar voor de mediasamenleving. Dit wist ik al toen ik dit essay begon te schrijven. Maar toch schrok ik van mijn analyse van recente sociologietijdschriften. Zo'n dertig jaar naar de introductie van computers en internet mogen we wel concluderen dat deze mediatiseringsgolf geleid heeft tot wezenlijke sociale veranderingen. Het is verbluffend dat de wetenschap die zich bezighoudt met menselijke samenlevingen daar niets mee doet. In de sociologie zou het net zo goed 1985 kunnen zijn, of zelfs 1965: een wereld van kranten en boeken, brieven, face-to-facegesprekken en een enkel telefoontje.

De vraag is natuurlijk: is dit erg? Ik heb hier betoogd van wel. Om te beginnen gaat het hier om veranderingen die raken aan de basisingrediënten van de sociologie: sociale actie en interactie, cultuur en sociale structuur. $\mathrm{Al}$ deze elementen afzonderlijk veranderen, en de verhouding tussen deze elementen ook. Het in stukjes knippen van media als context, data, spiegel of cultureel object, zoals gebeurt in sociologietijdschriften, weerhoudt ons ervan te zien hoe al deze verschuivingen met elkaar samenhangen. Met andere woorden: sociologen missen iets belangrijks.

Sociologen hebben in deze discussie ook iets te bieden. Het onderzoek en het maatschappelijk debat over de mediasamenleving wordt nu gedomineerd door media- en communicatiewetenschappers en politicologen. Zelfs economen en datawetenschappers zijn zichtbaarder in het debat. Terwijl het hier gaat om iets waar sociologen van oudsher goed in zijn: een sociale verschuiving die zich voordoet door de hele samenleving en over instituties en velden heen, waarin micro en macro, cultuur en structuur samenkomen. Juist de sociologie beschikt over de omvattende theoretische kaders, en over het methodologische inzicht en gereedschap om dergelijke verschuivingen te onderzoeken en te duiden. En juist de sociologie is van oudsher goed in meervoudige verklaringen: niet technologie of structuur of cultuur of politiek, maar en-en-en. 
Het duiden van een ingrijpende sociale verandering zou voor sociologen geen probleem hoeven te zijn. De discipline begon als een poging om greep te krijgen op een omwenteling die zeker zo snel en zo ingrijpend was als de huidige mediatisering: de modernisering en industrialisering van de negentiende eeuw. In de tweede helft van de twintigste eeuw bewoog de sociologie bovendien flexibel mee met de ontwikkeling van de moderne natiestaat. Dit vergde ook een herijking van methoden en concepten: de opkomst van statistische methoden, de verschuiving van 'grand theory' naar 'middle-range theory', en een arbeidsdeling tussen 'gewone' sociologen, toegepaste of beleidssociologen en 'kritische' sociologen. Maar juist deze discipline van de maatschappelijke omwenteling lijkt verstard in haar reactie op de laatste grote omwenteling: naar een mediasamenleving waarin modernisering niet meer de centrale kwestie is, en de natiestaat aan kracht verliest.

De sociologie mist door het negeren van mediatisering ook haar klassieke roeping. De founding fathers (en een enkele moeder) hadden altijd een dubbele agenda. Grondige sociale analyse, met de beste tools die voorhanden waren, ging altijd gepaard met tijdsdiagnose. Denk aan Webers Wetenschap als beroep (2015 [1917]), waarin hij, middenin de Eerste Wereldoorlog, deze dubbele roeping uiteenzet: sociologen moeten sociale ontwikkelingen analyseren en duiden, zonder te oordelen. Bij deze tijdsdiagnose hoort bovendien ook het doorprikken van mythen, grote claims en onbesuisde voorspellingen. In de huidige sterk geprofessionaliseerde sociologie is die duiding, met bijbehorende debunking, steeds meer uit beeld verdwenen. Hiermee hebben we een gat laten vallen dat anderen opvullen: media- en communicatiewetenschappers, politicologen, maar ook journalisten, opiniemakers, politici, techniekprofeten en marketeers. Vooral de laatste niet-wetenschappelijke duiders hebben vaak weinig boodschap aan zorgvuldige empirische analyse of het doorprikken van mythen.

Er staat ook werkelijk iets op het spel. De sociale verschuivingen waar we het over hebben zijn niet alleen boeiend uit wetenschappelijk oogpunt. Het gaat om grote veranderingen waarvan de implicaties nog lang niet duidelijk zijn. Inmiddels is al wel duidelijk dat de recente mediatisering iets heeft gedaan met de politiek waardoor die nooit meer hetzelfde zal zijn. Op andere gebieden zijn de consequenties lastig in te schatten, maar het is zeker niet alleen goed nieuws. Hoe beter en sneller we begrijpen wat er gebeurt, hoe meer greep we erop hebben. En zelfs behoedzame analyses wijzen erop dat de aankomende golf van 'dataficatie' kan leiden tot nog 
ingrijpender verschuivingen in de sociale orde. Zelfs de onverstoorbare mediasociologen Couldry en Hepp (2017: 212) spreken aan het einde van hun boek The Mediated Construction of Reality hun zorg uit: 'That is our concern: that under conditions of deep mediatization an ever more complex infrastructure of interdependent communication installs a datafied social order which relies more on infrastructural force (or near-force) than on the openly contestable legitimacy of norms'.

Ik eindig dit essay dan ook met een uitnodiging aan alle sociologen. Bij elk onderzoek dat je doet, voorstelt of begeleidt, stel jezelf de volgende vragen:

1 Ben je je bewust van de gemediatiseerde elementen in je onderzoek, bijvoorbeeld in je dataverzameling en -verwerking en je analysemethoden? Hoe zou dat je onderzoek kunnen beïnvloeden?

2 Zou je onderzoek gedaan kunnen worden met dezelfde methoden en concepten in het jaar 1975? Als dat het geval is: overweeg om het onderzoeksdesign aan te passen, zodat het design rekening houdt met specifiek hedendaagse (gemediatiseerde) elementen. Als het iets met (digitale) mediatisering te maken heeft, dan heb je daar tenminste naar gekeken.

3 Wat maakt het uit, zowel theoretisch als empirisch, dat je je onderzoek nu doet en niet in 1975? In hoeverre heeft dat te maken met de huidige mediasamenleving?

4 Meer strategisch: zou je onderzoek gepositioneerd kunnen worden ten opzichte van andere disciplines waarin media centraal staat, en zo ja, hoe?

5 In hoeverre verandert de onderzoeksvraag of het design als het expliciet wordt verbonden met een breder kader van mediatisering? Wordt het daar misschien interessanter van?

Het antwoord op deze vragen kan altijd 'nee' zijn. Maar ik kan me goed voorstellen dat veel sociologisch onderzoek niet alleen beter, maar ook interessanter wordt als het zich explicieter verhoudt tot een van de grootste sociale, politieke, culturele en economische verschuivingen van de laatste tijd. Mediatisering is te belangrijk om over te laten aan media- en communicatiewetenschappers, economen, data scientists en marketingonderzoekers. Maar vooral: het is te gevaarlijk om over te laten aan de journalistiek, de politiek, de tech pundits en het bedrijfsleven. 


\section{Noten}

1 De analyse omvat de volgende nummers: American Sociological Review jaargang 82, nummers 5, 6; jaargang 83, nummers 1, 2, 3, 4. British Journal of Sociology jaargang 68, nummers 2, 3, 4, S1; jaargang 69, nummers 1 en 2. European Societies jaargang 19, nummer 5; jaargang 20, nummers 1, 2, 3, 4. Sociologie jaargang 12, nummers 2, 3; jaargang 13, nummers 1, 2/3. In het geval van Sociologie zijn ook eerdere nummers meegenomen om de steekproef groot genoeg te maken.

\section{Literatuur}

Anderson, B. (2006) Imagined communities: Reflections on the origin and spread of nationalism. New York: Verso Books.

Bail, C., T.W. Brown en M. Mann (2017) Channeling hearts and minds: Advocacy organizations, cognitive-emotional currents, and public conversation. American Sociological Review, 82(6): 1188-1213.

Beldad, A., M. de Jong en M. Steehouder (2010) How shall I trust the faceless and the intangible? A literature review on the antecedents of online trust. Computers in Human Behavior, 26(5): 857-869.

Boucas, D. (2017) The state and the development of an information society: Greek policy and experience. The British Journal of Sociology, 68(3): 556-580.

Boyd, D. (2014) It's complicated: The social lives of networked teens. New Haven: Yale University Press.

Brayne, S. (2017) Big data surveillance: The case of policing. American Sociological Review, 82(5): 977-1008.

Chiaro, D. (2017) The language of jokes in the digital age: Viral humour. London: Routledge.

Collins, R. (2004) Interaction ritual chains. Princeton: Princeton University Press.

Crossley, N. en W. Bottero (2015) Social spaces of music: Introduction. Cultural Sociology, 9(1): 3-19.

Couldry, N. en A. Hepp (2017) The mediated construction of reality. Cambridge: Polity.

Daniels, J. en K. Gregory (red.) (2016) Digital sociologies. Briston: Policy Press.

Deuze, M. (2011) Media life. Media, Culture \& Society, 33(1): 137-148.

Dijck, J. van (2013a) 'You have one identity': Performing the self on Facebook and LinkedIn. Media, Culture \& Society, 35(2): 199-215.

Dijck, J. van (2013b) The culture of connectivity: A critical history of social media. Oxford University Press.

Golder, S. en M. Macy (2014) Digital footprints: Opportunities and challenges for online social research. Annual Review of Sociology, 40: 129-152.

Harambam, J. (2017) De/politisering van de Waarheid. Sociologie, 13(1): 73-92.

Haynes, J. en L. Marshall (2018) Reluctant entrepreneurs: Musicians and entrepreneurship in the 'new' music industry. The British Journal of Sociology, 69(2): 459-482.

Kroneberg, C. en F. Kalter (2012) Rational choice theory and empirical research: Methodological and theoretical contributions in Europe. Annual Review of Sociology, 38: 73-92.

Kuipers, G. en B. van der Ent (2016) Etnische humor en etnische relaties in Nederland. Sociologie, 12(2): 169-200.

Maloney, P. (2013) Online networks and emotional energy: How pro-anorexic websites use interaction ritual chains to (re)form identity. Information, Communication \& Society, 16(1): 105-124. 
Marwick, A. en D. Boyd (2011) I tweet honestly, I tweet passionately: Twitter users, context collapse, and the imagined audience. New Media \& Society, 13(1): 114-133.

McLuhan, M. (1994) Understanding media: The extensions of man. Boston: MIT Press.

Noordzij, K., K. van Eijck en P. Berkers (2016) Ik ben niet zo rijk, misschien wel gelukkiger. Sociologie, $12(3)$ : 249-274.

Oring, E. (2016) Joking asides: The theory, analysis, and aesthetics of humor. Boulder: University Press of Colorado.

Ortega, J. en P. Hergovich (2017) The strength of absent ties: Social integration via online dating. arXiv preprint arXiv:1709.10478.

Potârcă, G. en M. Mills (2015) Racial preferences in online dating across European countries. European Sociological Review, 31(3): 326-341.

Revers, M. en C. Brienza (2018) How not to establish a subfield: Media sociology in the United States. The American Sociologist, 49(3): 352-368.

Robinson, L. (2007) The cyberself: the self-ing project goes online, symbolic interaction in the digital age. New Media \& Society, 9(1): 93-110.

Rubio, F. (2014) Preserving the unpreservable: Docile and unruly objects at MoMA. Theory and Society, $43(6)$ : 617-645.

St. John, W. (2005) Seriously, the joke is dead. New York Times, 22 mei, https://www.nytimes. com/2005/05/22/fashion/sundaystyles/seriously-the-joke-is-dead.html.

Weber, M. (2015 [1917]) Wetenschap als beroep. Politiek als beroep. Nijmegen: Vantilt.

Zuiderveen Borgesius, F., D. Trilling, J. Moeller, B. Bodó, C. de Vreese en N. Helberger (2016) Should we worry about filter bubbles? Internet Policy Review. Journal on Internet Regulation, 5(1): https://ssrn.com/abstract=2758126.

\section{Over de auteurs}

Giselinde Kuipers is hoogleraar cultuursociologie aan de Universiteit van Amsterdam. Zij was redacteur en redactiesecretaris van Sociologie, en ook redacteur van een van de voorlopers van Sociologie, het Amsterdams Sociologisch Tijdschrift. Zij publiceerde onder meer over culturele mondialisering, media, humor, schoonheid en populaire cultuur.

E-mail: g.m.m.kuipers@uva.nl 